\title{
Contraceptive practices adopted by women attending an urban health centre
}

\author{
*Prateek SS, Saurabh RS
}

Department of Community Medicine, Shri Sathya Sai Medical College \& Research Institute, Kancheepuram

\begin{abstract}
Background: India was the first country in world to launch - The National Family Welfare Programme in1951 but even today the couple protection rate (CPR) is still not achieved as desired.

Objectives: To determine extent of awareness regarding contraception among married women. To estimate proportion of couples using contraceptive methods, identify reasons for their adoption \& non adoption and to assess unmet needs for contraception.
\end{abstract}

Methods: A cross sectional descriptive study of four months duration was conducted among married women in reproductive age group (15 - 49 years) attending general out-patient department in Urban Health Centre (UHC) employing universal sampling method. Participants not willing to respond and pregnant women were excluded. Total of 180 women were selected as study participants. Every woman was interviewed face to face with pre-tested questionnaire after taking informed consent. The data was analyzed by SPSS version 16.

Results: 94 (52.2\%) were in age group of 20 - 24years. 52.4\% of women were aware about contraceptive practices, of which only $32.2 \%$ of subjects were using contraceptive methods. Out of these subjects, $89.66 \%$ used temporary methods and $10.34 \%$ used permanent methods. Cu-T (41.37\%) was most preferred method. 93 subjects (51.6\%) had unmet need for contraception. Religion, education status and age at marriage were significantly associated with contraceptive usage.

Conclusion: The results suggest a significant Knowledge - Application Gap with regards to contraceptives knowledge and their actual usage in study participants. Almost fifty percent of the subjects had unmet need for contraception. This shows the need for more intense awareness campaigns for promoting contraceptive usage.

Keywords: contraception, unmet needs, knowledge - application gap, family planning.

African Health Sciences 2012; (4): 416 - 421 http://dx.doi.org/10.4314/ahs.v12i4.3

\section{Introduction}

India launched the National Family Welfare Programme in 1951 with the objective of reducing the birth rate to the extent necessary to stabilize the population at a level consistent with the requirement of the National economy. The Family Welfare Programme in India is recognized as a priority area, and is being implemented as a $100 \%$ centrally sponsored programme ${ }^{1}$.

Five states of Bihar, Uttar Pradesh, Madhya Pradesh, Rajasthan and Orissa, which constituted 44\%

\section{*Corresponding author:}

Dr. Prateek Saurabh Shrivastava

Department of Community Medicine

Shri Sathya Sai Medical College \& Research Institute

Ammapettai village

Thiruporur - Guduvancherry Main Road

Sembakkam Post

Kancheepuram - 603108

Tamil Nadu, India

Telephone: +919884227228

E-mail: prateekbobhate@yahoo.co.in of the total population of India in 1996, will constitute $48 \%$ of the total in 2016, according to projections. These states will contribute $55 \%$ of the total increase in population of the country during the period 1996-2016 ${ }^{2}$.

Family planning can reduce maternal mortality by reducing the number of pregnancies, the number of abortions, and the proportion of births at high risk ${ }^{3,4}$. It has been estimated that meeting women's need for modern contraceptives would prevent about one quarter to one-third of all maternal deaths, saving 140,000 to 150,000 lives a year ${ }^{5,6}$.

As per the projections by UN, India will become the most populous country by year 2045. Assessing the potential demand for contraceptive services is an important component of family planning programme management. The need to control increasing population so as to mitigate the adverse impact of population growth on the economic development was recognised by the planners since the very beginning of planning in the country ${ }^{7}$.

African Health Sciences Vol 12 Issue 4 December 2012 
In Philippines however, low-income women experience great difficulty accessing modern family planning methods. In addition to cultural and religious barriers, family planning program planners also face formidable legal barriers due to the country's own policies ${ }^{8}$. The extent of acceptance of contraceptive methods still varies within societies and also among different castes and religious groups. The factors responsible for such varied picture operate at the individual, family and community level with their roots in the socio-economic and cultural milieu of Indian Society. Recent evidence from Ethiopia, where the majority of the population live in rural areas, indicates that the country's contraceptive prevalence rate could double if the current community based reproductive health program were expanded to include provision of family planning ${ }^{9}$. Hence, the present study was designed to find out the contraceptive prevalence and identify the different variables which affect the contraceptive prevalence among the urban slum community in Mumbai.

\section{Methods}

A cross sectional descriptive study of four months duration was conducted among married women in reproductive age group (15 - 49 years) attending General Out Patient Department in Urban Health Centre (UHC). UHC is a service delivery centre attached to a tertiary care centre (Medical College) where services like implementation of National health programmes (Vector Borne Disease, Family Welfare, Immunization, Tuberculosis, Leprosy, Sexually Transmitted Infections, HIV-TB collaborative services, Reproductive and Child Health services along with Outpatient department services for general public) is carried out.

The method of sampling was Universal Sampling i.e. all married women in reproductive age group (15 - 49 years) who have attended the UHC during the study period were selected as study subjects. Exclusion criterion: 1) Participants not willing to respond even after requesting and ensuring confidentiality were excluded from the study. 18 females were thus excluded from the study. 2) Pregnant women were excluded from the study. 7 women were thus excluded.

A total of 180 women were selected as study participants. Every woman was interviewed face to face with pre-tested questionnaire after taking an informed consent. The questionnaire included sociodemographic details and details regarding contraceptive practices. Utmost care was taken to maintain privacy and confidentiality. Modified Kuppuswamy scale was used for classification of socio-economic status into lower, middle and upper ${ }^{10}$.

African Health Sciences Vol 12 Issue 4 December 2012
Information on knowledge of contraception was collected in two ways. First, respondents were asked to spontaneously mention all the methods of contraception that they had heard of. For methods not mentioned spontaneously, the interviewer described the method and probed for whether the respondent recognized it. Respondents who were able to spontaneously mention at least two contraceptive measures (temporary/permanent) were accepted as having knowledge about contraceptive measures. Also, if the respondents were able to recognize the method on probing, it was accepted as having knowledge about contraceptive measures.

Information was thus collected on the knowledge of female and male sterilization, the pill, the IUD, injectables, male condoms, female condoms, emergency contraception, and two traditional methods (rhythm and withdrawal).

Unmet needs has been defined as those women who are fecund and sexually active but are not using any method of contraception, and report not wanting any more children. The concept of unmet need points to the gap between women's reproductive intentions and their contraceptive behavior ${ }^{11}$.

\section{Ethical considerations}

Ethical clearance was obtained from the Institutional Ethics committee prior to the start of the study. Written informed consent was obtained from the study participants before obtaining any information from them. Utmost care was taken to maintain privacy and confidentiality.

\section{Data analysis}

Data entry and statistical analysis was done using SPSS version 16. The data collected using the above mentioned measures were analyzed using frequencies and percentages. Chi square test was used for testing the significance of association at $\mathrm{P}$ value of 0.05 and 0.001 .

\section{Results}

Table 1 shows that out of the total 180 subjects that participated in the study only $94(52.2 \%)$ married women were having knowledge about the contraceptives while remaining $86(47.8 \%)$ were having no knowledge regarding the same. Thus it gives a clear indication that there is a great need of community based Information Education \& Counseling (IEC) activities in the study area. Percentage of subjects with contraceptive knowledge was $52.22 \%$ while that of contraceptive usage was $32.22 \%$ suggesting Knowledge - Application Gap. 
Table 1: Contraceptive knowledge among study subjects

\begin{tabular}{lll}
\hline $\begin{array}{l}\text { Contraceptive } \\
\text { knowledge }\end{array}$ & Number & $\begin{array}{l}\text { Percentage } \\
(\%)\end{array}$ \\
\hline Yes & 94 & $52.2 \%$ \\
No & 86 & $47.8 \%$ \\
Total & 180 & $100 \%$ \\
\hline
\end{tabular}

Table 2 shows the relationship between the various socio-demographic parameters and contraceptive usage. Age of the study participants was found to be significantly associated with contraceptive usage depicting that out of the 24 participants less than 20 years only $6(25 \%)$ were using any form of contraceptives. Out of the 124 Muslim study subjects, only $34(27.4 \%)$ were using contraceptives suggesting that IEC activities needs to be strengthened in Muslim community as $90(72.6 \%)$ were not using any of the temporary or permanent contraceptives. Both subject's education status and their husband's education status was found to be significantly associated with contraceptive usage suggesting that literacy status can definitely have an impact on motivating a couple to adopt any contraceptives method for spacing. Out of the 76 subjects who were from the lower socioeconomic class only $17(22.3 \%)$ were actually using contraceptives in comparison to $15(65.2 \%)$ subjects out of the 23 from the upper class. There was no association observed between age at marriage / birth order of the study subjects and contraceptive usage. When relationship between age at first pregnancy and contraceptive usage was considered it was observed that out of the 68 married women who had their first pregnancy at less than 20 years of age, only $15(22.1 \%)$ were using contraceptives which needs to be seriously looked upon as it not only increases the number of child a woman will bear but can also have a serious impact on the health status of the mother.

Table 2: Socio demographic factors and contraceptive usage

\begin{tabular}{|c|c|c|c|c|c|}
\hline \multirow[t]{2}{*}{ Socio demographic parameters } & & \multicolumn{2}{|c|}{ Contraceptive usage } & \multirow[t]{2}{*}{ Total } & \multirow[t]{2}{*}{$\mathrm{p}$ value } \\
\hline & & Yes & No & & \\
\hline \multirow[t]{4}{*}{ Age (years) } & $<20$ & $6(25.0 \%)$ & $18(75.0 \%)$ & $24(100.0 \%)$ & $<0.05$ \\
\hline & $20-24$ & $21(22.3 \%)$ & $73(77.7 \%)$ & $94(100.0 \%)$ & \\
\hline & $25-29$ & $25(61.0 \%)$ & $16(39.0 \%)$ & $41(100.0 \%)$ & \\
\hline & $>30$ & $6(28.6 \%)$ & $15(71.4 \%)$ & $21(100.0 \%)$ & \\
\hline \multirow[t]{2}{*}{ Religion pregnancy } & Hindu & $24(42.9 \%)$ & $32(57.1 \%)$ & $56(100.0 \%)$ & $<0.05$ \\
\hline & Muslim & $34(27.4 \%)$ & $90(72.6 \%)$ & $124(100.0 \%)$ & \\
\hline \multirow[t]{5}{*}{ Subjects education } & Illiterate & $8(15.6 \%)$ & $43(84.4 \%)$ & $51(100.0 \%)$ & $<0.05$ \\
\hline & Primary & $1\left(14.2^{\%} \%\right)$ & $6(85.8 \%)$ & $7(100.0 \%)$ & \\
\hline & Secondary & $17(34 \%)$ & $33(66 \%)$ & $50(100.0 \%)$ & \\
\hline & $\begin{array}{l}\text { Higher } \\
\text { secondary }\end{array}$ & $22(39.2 \%)$ & $34(61.8 \%)$ & $56(100.0 \%)$ & \\
\hline & $\begin{array}{l}\text { Graduate \& } \\
\text { above }\end{array}$ & $10(62.5 \%)$ & $6(37.5 \%)$ & $16(100.0 \%)$ & \\
\hline \multirow{3}{*}{$\begin{array}{l}\text { Socio-economic } \\
\text { status }\end{array}$} & Lower & $17(22.3 \%)$ & $59(77.7 \%)$ & $76(100.0 \%)$ & $<0.05$ \\
\hline & Middle & $26(32.1 \%)$ & $55(67.9 \%)$ & $81(100.0 \%)$ & \\
\hline & Upper & $15(65.2 \%)$ & $8(34.8 \%)$ & $23(100.0 \%)$ & \\
\hline \multirow[t]{3}{*}{ Age at marriage } & $<20$ & $33(30.2 \%)$ & $76(69.7 \%)$ & $109(100 \%)$ & $>0.05$ \\
\hline & $20-24$ & $17(27.4 \%)$ & $45(72.5 \%)$ & $62(100 \%)$ & \\
\hline & $\geq 25$ & $4(44.4 \%)$ & $5(55.5 \%)$ & $9(100 \%)$ & \\
\hline \multirow[t]{2}{*}{ Age at first pregnancy } & $<20$ years & $15(22.1 \%)$ & $53(77.9 \%)$ & $68(100.0 \%)$ & $<0.05$ \\
\hline & $\geq 20$ years & $43(38.4 \%)$ & $69(61.6 \%)$ & $112(100.0 \%)$ & \\
\hline \multirow[t]{3}{*}{ Birth order } & 1 & $20(27.4 \%)$ & $53(72.6 \%)$ & $73(100.0 \%)$ & $>0.05$ \\
\hline & 2 & $28(38.9 \%)$ & $44(61.1 \%)$ & $72(100.0 \%)$ & \\
\hline & $\geq 3$ & $10(28.6 \%)$ & $25(71.4 \%)$ & $35(100.0 \%)$ & \\
\hline \multirow[t]{5}{*}{ Husbands education } & Illiterate & $3(5.9 \%)$ & $48(94.1 \%)$ & $51(100.0 \%)$ & $<0.01$ \\
\hline & Primary & $7(22.6 \%)$ & $24(77.4 \%)$ & $31(100.0 \%)$ & \\
\hline & Secondary & $24(47.1 \%)$ & $27(52.9 \%)$ & $51(100.0 \%)$ & \\
\hline & $\begin{array}{l}\text { Higher } \\
\text { secondary }\end{array}$ & $17(50.0 \%)$ & $17(50.0 \%)$ & $34(100.0 \%)$ & \\
\hline & $\begin{array}{l}\text { Graduate } \\
\text { and above }\end{array}$ & $7(53.8 \%)$ & $6(46.2 \%)$ & $13(100.0 \%)$ & \\
\hline
\end{tabular}


Table 3 shows the distribution of various contraceptive methods available depending on the age of study subjects. Overall only $58(32.2 \%)$ were using contraceptive measure of any sort. Copper- $T$ was the most common contraceptive measure used by almost $24(41.3 \%)$ of study participants. Only 8 $(13.8 \%)$ subjects less than 20 years of age were using any contraceptives. Also only $6(10.3 \%)$ subjects have adopted permanent contraceptives as a mode of limiting.

Table 3 Age-wise contraceptive users among study subjects

\begin{tabular}{llllll}
\hline Age (years) & \multicolumn{2}{c}{ Method used } & Total \\
& Condom & Cu T & $\begin{array}{c}\text { Oral Contrac- } \\
\text { eptive pills }\end{array}$ & $\begin{array}{l}\text { Tubal } \\
\text { ligation }\end{array}$ & \\
\hline$<20$ & $4(50 \%)$ & $1(12.5 \%)$ & $3(37.5 \%)$ & $0(0 \%)$ & $8(100 \%)$ \\
$20-24$ & $7(36.8 \%)$ & $8(42.1 \%)$ & $3(15.7 \%)$ & $1(5.2 \%)$ & $19(100 \%)$ \\
$25-29$ & $5(25 \%)$ & $11(55.5 \%)$ & $1(5 \%)$ & $3(15 \%)$ & $20(100 \%)$ \\
$>30$ & $3(27.2 \%)$ & $4(36.3 \%)$ & $2(18.1 \%)$ & $2(18.1 \%)$ & $11(100 \%)$ \\
Total & $19(32.7 \%)$ & $24(41.3 \%)$ & $9(15.5 \%)$ & $6(10.3 \%)$ & $58(100 \%)$ \\
\hline
\end{tabular}

Table 4 shows the reasons cited by the study subjects for either using or not using the contraceptives. $21(36.2 \%)$ of the participants said that they prefer using condom as a mode of contraception as it is easily available while for $\mathrm{Cu}-\mathrm{T}$ almost $16(27.5 \%)$ subject were of the opinion that it offers long time protection. When the remaining 122 women were asked about the reason for non usage, 86(70.5\%) said that they were not having any knowledge regarding various contraceptive methods. About $26(21.3 \%)$ participants said that they were not using any contraceptive because they are afraid of the side effects of contraceptives. 93 subjects $(51.6 \%)$ had unmet need for contraception.

Table 4: Reasons for contraceptive usage and non usage

\begin{tabular}{|c|c|c|c|}
\hline \multicolumn{2}{|c|}{ Reason for contraceptive usage } & \multirow{2}{*}{$\begin{array}{l}\text { Number* }(n=58) \\
21\end{array}$} & \multirow{2}{*}{$\begin{array}{l}\text { Percentage } \\
36.2 \%\end{array}$} \\
\hline Condom & Easily available & & \\
\hline Tubal ligation & Family completed & 6 & $10.3 \%$ \\
\hline \multirow[t]{2}{*}{ OC Pills } & Comfortable & 7 & $12 \%$ \\
\hline & Not allowed other me & ily 2 & $3.4 \%$ \\
\hline \multirow[t]{3}{*}{$\mathrm{Cu} \mathrm{T}$} & Husband's preference & 6 & $10.3 \%$ \\
\hline & One time insertion & 14 & $24.1 \%$ \\
\hline & Long term protection & 16 & $27.5 \%$ \\
\hline \multicolumn{2}{|c|}{ Reason for contraceptive non usage } & Number* $(n=122)$ & Percentage \\
\hline \multicolumn{2}{|c|}{ Afraid of side effects } & 26 & $21.3 \%$ \\
\hline \multicolumn{2}{|c|}{ Want to conceive } & 29 & $23.8 \%$ \\
\hline \multicolumn{2}{|l|}{ No knowledge } & 86 & $70.5 \%$ \\
\hline \multicolumn{2}{|c|}{ Husband out of town for work } & 10 & $8.2 \%$ \\
\hline \multicolumn{2}{|l|}{$\underline{\text { Familial pressure }}$} & 17 & $13.9 \%$ \\
\hline
\end{tabular}

*Multiple responses were obtained

\section{Discussion}

In the current study only $58(32.2 \%)$ subjects were using contraceptives of any form in comparison to a study done in south-west Nigeria where point prevalence rate of contraception was $66.3 \%{ }^{12}$. Also in a study carried out in Samaru community in Nigeria contraceptive prevalence was $12.5 \%{ }^{13}$. In a descriptive study carried out amongst women in reproductive age group in Sudan current usage of contraception was found to be $21.3 \%{ }^{14}$. According to findings of National Family Health Survey - 3, usage of any mode of contraception amongst women in reproductive age group in urban area in India was found to be $64 \%{ }^{15}$.

In our study it was observed that $86(70.5 \%)$ subjects said that they were not having any knowledge regarding various contraceptive methods. Similar 
findings were observed in a study done in urban slum of Maharashtra where $57.6 \%$ subjects revealed that lack of information about contraceptive method and its sources were the common reasons for nonacceptance of contraception ${ }^{16}$.

In a study carried out amongst European women, ${ }^{(17)}$ oral contraceptives was the most common contraceptive used in Germany (54.3\%), France $(50.5 \%)$ and Sweden $(34.6 \%)$ as compared to $\mathrm{Cu}-\mathrm{T}$ which was the most common contraceptive utilized in $24(13.3 \%)$ study participants in the present study. While in studies done in Andhra Pradesh and Eastern Delhi, tubectomy and condom $(33.9 \%)$ were the most preferred methods of contraception respectively ${ }^{18,19}$.

In the current study significant association was observed between age groups of study participants and choice of contraceptive methods while no significant association was observed between age of marriage and contraceptive usage. Similar findings were observed in a study carried out in a Muslim predominant community in Mewat, Haryan $^{20}$. In a study conducted in Dehradun it was observed that younger age of the women, illiteracy, Muslim religion, no living son in the family and experience of child loss were found to be associated with low use of contraception ${ }^{21}$. A significant association was found between contraceptive acceptance and literacy status, occupation, type of family, socioeconomic status and age at marriage in married women in reproductive age group in the village Chanai, Beed district ${ }^{22}$. In a review of the literature on the barriers for fertility regulation from a consumer perspective identifies limited method choice, financial costs, women's status, medical and legal restrictions, provider bias and misinformation as reasons for non-use of contraception ${ }^{(23)}$.

In our study 93 subjects $(51.6 \%)$ had unmet need for contraception. Out of which, $52(28.9 \%)$ subjects had unmet need for spacing and rest 41 $(22.7 \%)$ had unmet need for limiting. In a study carried out in both rural and urban area of Gwalior district the unmet need of family planning was found to be $21.70 \%{ }^{24}$. In a descriptive study carried out amongst women in reproductive age group in Sudan unmet need for contraception was found to be $30.7 \%{ }^{14}$. The overall unmet need for family planning was $25.4 \%$ in a study carried out in resettlement colony in eastern Delhi ${ }^{19}$. The higher percentage of unmet need in our study was mainly because of lack of knowledge about contraception (70.5\%), followed by fear of side effects $(21.3 \%)$ and familial pressures $(13.9 \%)$. In a review on unmet need for family planning in developing countries found that substantial increases in contraceptive prevalence can be achieved in the absence of changes in the demand for children by meeting the existing unmet need ${ }^{25}$. In the present study none of the study participants reported that their partners interfere with their birth control measures (i.e. none of the husbands interfered with the choice of contraceptives by the women) while in a study carried out in United States, women reporting that their partners interfere with their birth control were nearly twice as likely as women without interfering partners to report those partners being involved in their contraceptive services ${ }^{26}$.

The study had its limitation in the form that it was a centre based study. A community based study would give more generalizable results. Also partner preferences were not taken into account. An extension of the same study involving partners can be planned in future.

\section{Conclusion}

There is a tremendous need of incorporating IEC activities as a part of National Family Welfare Programme. These IEC activities should not be for a specific occasion rather a sincere effort should be taken by the entire health team to not miss even a single opportunity be it a Antenatal visit or postnatal visits or immunization sessions or even general OPD / Sexually Transmitted Infections (STI) clinic. Spousal involvement throughout the antenatal, intra-natal and postnatal period through separate husband craft clinics emphasizing responsible parenthood should be promoted. Every effort should be taken to correct the myths and misconceptions associated with contraceptive measures. Community Health Volunteers, Anganwadi workers and the proposed Urban Social Health Activists under National Urban Health Mission should undergo specialized training in Family Planning. Special contraception promotion campaigns can be organized on various occasions like World Population Day, Children's‘ Day and Breast Feeding Week.

\section{References}

1. National Family Welfare Programme. http:// pbhealth.gov.in/pdf/FW.pdf

2. Family Welfare Programme. http:// planningcommission.nic.in/plans/mta/mta9702/mta-ch17.pdf 
3. Levine R, Langer A, Birdsall N, Matheny G, Wright, M, Bayer A. Contraception. In: Jamison DT, Breman, JG, Measham AR, et al., eds. Disease Control. Priorities in Developing Countries. New York: Oxford University Press; 2006:1075-1090. Available at: www.dcp2.org/pubs/DCP/57/ FullText.

4. Lule E, Singh S, Chowdhury SA. Fertility Regulation Behaviors and Their Costs: Contraception and Unintended Pregnancies in Africa and Eastern Europe \& Central Asia. HNP Publication, World Bank: Washington DC, USA . December 2007

5. Singh S, Darroch JE, Vlassof M, Nadeau J. Adding It Up: The Benefits of Investing in Sexual and Reproductive Health Care. New York: Alan Guttmacher Institute; 2003. Available at: www.guttmacher. org/pubs/addingitup.pdf.

6. Collumbien M, Gerressu M, Cleland J. Non-use and use of ineffective methods of contraception. In: Ezzati M, Lopez AD, Rodgers A, Murray CJL, eds. Comparative Quantification of Health Risks: Global and Regional Burden of Disease Attributable to Selected Major Risk Factors. Geneva: WHO; 2004:1255-1320.

7. Evaluation study on family programme. http:// planningcommission.nic.in/reports/peoreport/ cmpdmpeo/volume1/135.pdf

8. Mello MM, Powlowski M, Nanagas JM, Bossert T. The role of law in public health: the case of family planning in the Philippines. Social Science and Medicine 2006; 63(2): 384-396.

9. Tawye Y, Jotie F, Shigu T, Ngom P, Maggwa N. The potential impact of community based distribution programmes on contraceptive uptake in resource-poor settings: evidence from Ethiopia. African Journal of Reproductive Health 2005; 9(3): 1526.

10. Park JE, Park K. Text Book of Preventive and Social Medicine. $21^{\text {st }}$ ed. M/s.Banarsidas Bhanot Publishers, Jabalpur; 2011, pp. 638-640.

11. Millennium Development Goal Indicators. Available from: http://unstats.un.org/unsd/mdg/ Metadata.aspx? IndicatorId $=0 \&$ Series $I d=778$

12. Olugbenga-Bello AI, Abodunrin OL, Adeomi AA. Contraceptive Practices among women in rural communities in South-Western Nigeria. Global Journal of Medical research 2011; 11(2): 1-8.

13. Aliyu AA, Shehu AU, Sambo MN, Sabitu K. Contraceptive knowledge, attitudes and practice among married women in Samaru community, Zaria, Nigeria. East Afr J Public Health 2010; 7(4): 342-344.

14. Patil SS, Durgawale MP, Patil SR. Epidemiological Correlates of Unmet Need for Contraception in
Urban Slum Population. Al Ameen J Med Sci 2010; 3(4): 312-316.

15. Key indicators for India from NFHS-3. Available from: http://www.nfhsindia.org/pdf/India.pdf

16. Umbeli T, Mukhtar A, Abusalab MA. Study of unmet need for family planning in Dar Assalam, Sudan 2001. Eastern Mediterranean Health Journal 2005; 11(4): 594-600.

17. De Irala J, Osorio A, Carlos S, Lopez-Del Burgo C. Choice of birth control methods among European women and the role of partners and providers. Contraception 2011; 84(6): 558-564.

18. Varma GR, Rohini A. Attitude of Spouse towards Family Planning: A Study among Married Men and Women of a Rural Community in West Godavari District, Andhra Pradesh. Anthropologist 2008; 10(1): 71-75.

19. Saini NK, Bhasin SK, Sharma R, Yadav G. Study of unmet need for family planning in a resettlement colony of east Delhi. Health and Population-Perspectives and Issues 2007; 30(2): 124-133.

20. Gaur D, Goel MK, Goel M. Contraceptive practices and related factors among females in predominantly rural Muslim area of North India. The Internet Journal of World Health and Societal Politics 2008; 5(1).

21. Chandra RAK, Kandpal SD, Negi KS. Epidemiological Correlates of Contraceptive Prevalence in Rural Population of Dehradun District. Indian Journal of Community Medicine 2005; 30(2): 60-62.

22. Murarkar SK, Soundale SG. Epidemiological correlates of contraceptive prevalence in married women of reproductive age group in rural area. National Journal of Community Medicine 2011; 2(1): 78-81.

23. Campbell M, Sahin-Hodoglugil N, Potts M. Barriers to fertility regulation: A review of the literature. Studies in Family Planning 2006; 37(2): 8798.

24. Srivastava DK, Pramod G, Roli G, Gour N, Bansal M. A study to assess the unmet needs of family planning in Gwalior district and to study the factors that helps in determining it. National Journal of Community Medicine 2011; 2(1): 28-31.

25. Casterline J, Sinding S. Unmet need for family planning in developing countries and implications for population policy. Population and Development Review 2000; 26(4): 691-723.

26. Kavanaugh ML, Lindberg LD, Frost J. Factors influencing partners' involvement in women's contraceptive services. Contraception 2012; 85(1): 83-90. 